\title{
The structure design and simulation analysis for the corn seedling mechanism of transplanting machine
}

\author{
Song Yujie ${ }^{1, a}$, Hu Jun ${ }^{2, b}$ \\ ${ }^{1}$ Song Yujie (1991 -), Henan province in China. Hei Longjiang BaYi Agricultural University. College \\ of engineering, 163319. \\ ${ }^{2}$ Hu Jun (1972 -), male (ethnic Han), Jiangsu province in China, master tutor. Hei Longjiang BaYi \\ Agricultural University. College of engineering, 163319. \\ a735753165@qq.com, b gcxykj@126.com
}

Keywords: transplanting machine; Seedling mechanism with; paper pot seedling

\begin{abstract}
In order to achieve the efficient transplanting of corn pot seedling in the field, and to avoid the seedlings injuries result from separation between seedling and pot with traditional ways. A kind of seedling mechanism is designed which the main body is disc cutter, and the structure of the disc cutter is focused on, then modeling and simulation analysis are finished with UG. Simulation results show that the institution can separate a row of paper pot seedling into single and sent it to seedling guide tube. It lays a foundation for the development of the automatic maize transplanting machine.
\end{abstract}

\section{Introduction}

Corn is not only major food crop, but also the important raw material for chemical industry, fuel, etc. It is visible that improve the yield of corn plays an important role in food security. Compared to direct seeding, transplanting can increase accumulated temperature, the time to sow will be earlier at the same time the crop growth period will prolong, and it is more beneficial to the improvement of yield and quality.

Most existing maize transplanters are semi-automatic, and it need artificial feeding seedlings, the intensity of labor is big and efficiency is low. Automatic transplanting machines are complex and expensive, so it does not avail the widespread application of mechanized transplanting. Seedling mechanism is an important part of automatic transplanting machine, also is the key to distinguish automatic and semi-automatic transplanter. Therefore, the goal is to design a seedling institution that can cut the paper pot and avoid seedlings injuries which result from separation between seedling and pot. Seedling mechanism is combined with Tube type transplanter and lays a foundation for the development of the automatic maize transplanter.

\section{Overseas and Domestic Research Status}

Foreign research status about transplanting machine and seedling mechanism

In the early 20th century, some countries in Europe began to appear in seedling planting machine; Late 30 s, Europe and the United States used plant organization instead of manual labor; after the 50 s, European countries develop a variety of different structure forms of semi-automatic transplanting machine; until the $1980 \mathrm{~s}$, semi-automatic transplanting machine has been widely used in agricultural production in the west ${ }^{[1]}$, such as the production plant machine (OMTA) produced by the Checchi\&Magli company in Italy, Italy production NADRI corn pot seedling transplanting machine, etc. ${ }^{2]}$, among them, when OMTA planting machine working, seedling clip clamping seedlings into the slide down then do rotary motion, finally will send seedlings into a ditch, but the efficiency is low.

For seedling mechanism in abroad, the United States developed countries research pot seedling transplanting technology started relatively early, such as the United States KUTZ University design 
a kind of automatic seedling robot, with high survival rate after transplanting but low efficiency; South Korea has developed a single arm of five-bar mechanism, structure is simple but reliability is poor; Japanese machinery company research and develop a combined-type seedling mechanism with automatic gear which can realize hole tray seedlings, take seedlings and seedlings function for one time, but large institutions vibration lead to the decline of success rate.

Taken together, there is relatively high degree in automation of foreign transplanting machine and seedling mechanism, but the structure of machine is complicated, so it is not suitable for popularization and application in our country.

\section{Current research status about transplanter and seedling mechanism with in China}

Dry land transplanting machine in China began in the 1950 s. In the 1970s, naked root transplanting machinery was developed, in the $80 \mathrm{~s}$ semi-automatic vegetable transplanting machine was developed successfully ${ }^{[3]}$. With the development of agricultural mechanization, transplanting technology from manual operation to the semi-automatic operation, then to fully automated machinery operation Molding semi-automatic transplanter includes ${ }^{[4-5]} 2 \mathrm{z}-2$ multi-purpose pot seedling transplanting machine, 2 zt - 2 beet paper tube transplanting machine, 2 ZDF tubular type semi-automatic guide seedlings transplanting machine, and 2 yz - 40 hanging basket type pot seedling transplanting machine, etc. Typical automatic transplanting machine is a seedling mechanism which controlled by the connecting rod and gear groove designed by domestic Wu Fuhua $^{[6]}$, it has been verified by experiment that the automatic hole tray seedlings transplanting can take seedlings, send seedlings, planting and covering for one time.

Typically seedling mechanism ${ }^{[7-9]}$ includes taking seedling mechanism with four bar clips designed by $\mathrm{Xu}$ Liming, mechanism with Planetary gear train projected by $\mathrm{Yu}$ professor, and mechanism that Suitable for plastic Pot seedling designed by Gong Chengyu. The plunger type seedling institutions studied by Gu Wenjun are in a high efficiency, and hydraulic roof rod through Bo Pan drain at the bottom of the ejection, then hydraulic push the entire row of seedlings out through the drain at the bottom of Bo Pan, then transport agencies will send next row of pot seedling to the specified location to repeat ejection process.

Above all, seedling mechanism that can avoid separation between pot and seedling need to be developed. Based on the paper pot seedling transplanting technology, seedling mechanism with disc cutter as the main body should be designed. This article focuses on design and simulation of seedling mechanism.

\section{The design of the seedling mechanism}

\section{The overall design of seedling mechanism}

To meet the requirements of working, the structure of seedling mechanism is shown in figure 1. Cutter knife 1 rotate at a constant speed driven by motor, disc cutter cutting paper Bo Pan when it just moves to the end of the conveyor belt; Stepper motor controls intermittent movement of conveyor chain, to ensure conveyor chain stops movement when cutting pot seedling, and continue to send seedling to tube after completing cutting. Leave gaps between the end of conveyor chain and tube in order to make the disc cutter rotary motion at a constant speed smoothly. Connection board was set on tube 7 to insure the pot seedling slipped to guide tube automatically.

\section{Disc cutter}

Disc cutter is the working part separating the row of paper pot into single. Center hole connects to the power output shaft; cutter head is installed in the bottom of the rotation axis and concentric with it. The blade was installed on the disk evenly and blades protrude the knife for a distance. The disc cutter is shown in figure 2, and the blades change conveniently to ensure the cutting quality. The disc cutter rotates at a constant speed driven by the motor, and knife does a circular motion around coiled center hole. The tip trajectory is the green line. 

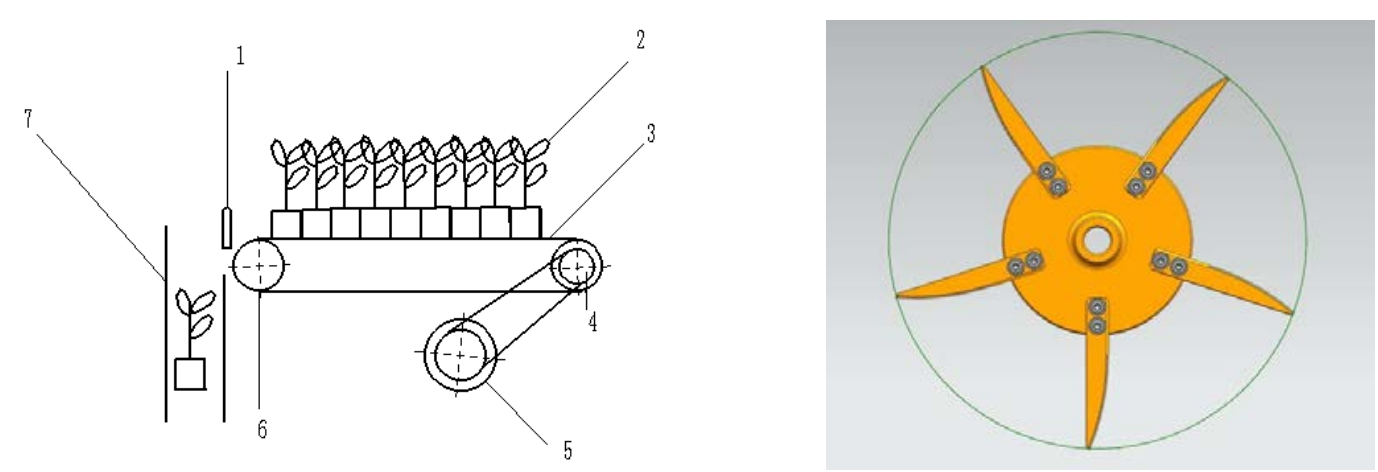

1. Disc cutter 2. seedling 3. Conveyor chain 4. Driving wheel 5. Motor 6. Driven pulley 7. Guide tube

Fig.1 seedling mechanism diagram

Fig.2 disc cutter and point trajectory

\section{Conveying equipment}

Conveyer carries pot seedling and transports them to the guide tube. The chain add baffle on both sides and baffle width can be adjusted. The top of the baffle Stretch to the inside of the 3mm, so it can guarantee the stability of paper pot conveyor and avoid paper pot seedling dumped down in the process of cutting. Conveyer is shown in figure 3. Compared with conveyor belt, conveyor chain is more wear-resisting, so it is more suitable for farmland homework. Conveying equipment does intermittent movement, and cooperates with the disc cutter to complete the seedlings.

\section{Analysis of disc cutter parameter}

The movement of the disc cutter includes rotating cutter center motion and linear motion with transplanting machine, so any point on the cutter path curve is trochoid. The center of the knife is the origin of coordinates; horizontal direction is set as $\mathrm{X}$ axis, and direction of transplanting machine as $\mathrm{Y}$ axis. One point on the cutter $\mathrm{m}$ over the trajectory of cycloid equation is shown in the formula (1).

$$
\left\{\begin{array}{l}
x=R \cos \omega t \\
y=R \sin \omega t+V_{j}
\end{array}\right.
$$

In the formula: $\mathrm{t}$ is time, $\mathrm{s}$

$\omega$ is the angular velocity, $\omega=2 \pi \cdot \mathrm{n} / 60, \mathrm{rad} / \mathrm{s}$

$\mathrm{V}_{\mathrm{j}}$ is machine speed, $\mathrm{m} / \mathrm{s}$

$\mathrm{R}$ is the knife dish along the rotation radius of turning center, $\mathrm{m}$

The movement of point $\mathrm{m}$ includes rotating cutter center motion and linear motion, the equation shown as the formula (2).

$$
\vec{V}=\vec{V}_{m}+\vec{V}_{j}
$$

In the formula: $\mathrm{V}$ is speed for cutting knife, $\mathrm{m} / \mathrm{s}$.

$\mathrm{V}_{\mathrm{m}}$ is the rotation of the cutting knife, $\mathrm{m} / \mathrm{s}$.

The disc cutter speed analysis: Reasonable disc cutter speed plays an important role in the improvement of efficiency. There is important significance to enhance efficiency to reasonable cutter disk rotational speed. If speed is too low, it will lead to lower speed of the transplanting operation; if speed is too high, it may damage the seedling. The rotation of cutter radius times the speed of the cutter is cutting knife rotation speed, and the direction perpendicular to the cutter's attachment to the center of the cutter. Speed of transplanting machine is fixed, when the rotation direction of the cutting knife in contrast to the direction of transplanting machine, cutter velocity is smallest, and computational formula is 3 .

$$
\mathrm{V}_{\min }=\mathrm{V}_{\mathrm{m}}-\mathrm{V}_{\mathrm{j}}
$$

In the formula: $V_{\min }$ is the minimum linear velocity of cutter, $\mathrm{m} / \mathrm{s}$.

Cutter radius $r$ is calculated using the formula 4.

$$
v=2 \pi \omega r
$$

Cutter diameter analysis: There is no support for rotary cutting, so the cutting speed has higher 
requirements. The expression of cutter diameter can be received according to the relationship between linear velocity and rotation speed.

$$
\mathrm{D}=\frac{\mathrm{V}}{\mathrm{n} \pi}
$$

In the formula: $\mathrm{n}$ is cutting wheel rotation speed; and $\mathrm{V}$ is cutting speed.

Combination of corn seedling agronomic traits and reliability requirements of blade, etc., the basic parameters of cutting knife are determined, as shown in table 1.

Table 1 the parameters of the cutting knife

\begin{tabular}{ll}
\hline The basic parameters & The parameter value \\
\hline The blade material & $65 \mathrm{mn}$ steel \\
The knife dish material & $45 \#$ steel \\
Cutter diameter & $200 \mathrm{~mm}$ \\
The blade length & $85 \mathrm{~mm}$ \\
The blade width b & $14 \mathrm{~mm}$ \\
The blade thickness d & $3 \mathrm{~mm}$ \\
The blade number & 5 \\
\hline
\end{tabular}

\section{The simulation analysis}

\section{The establishment of the virtual prototype}

Modeling assembly and simulation are completed in UG, and then constraints and load are added. Assembly drawing is shown in figure 4.

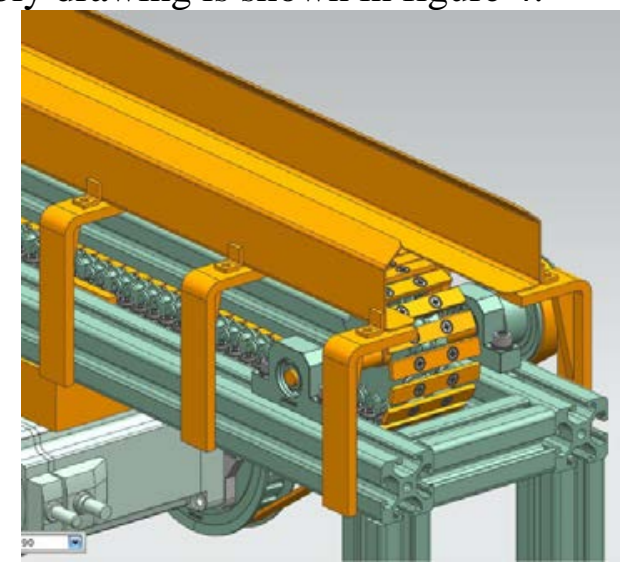

Fig.3 conveyor chain

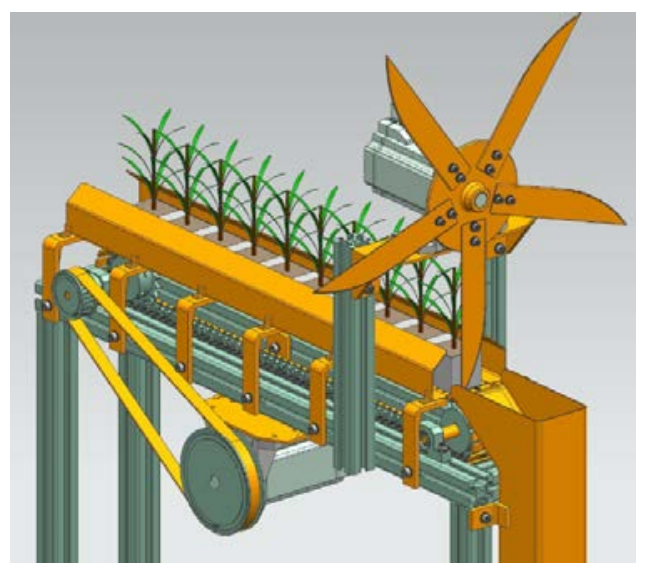

Fig.4 Assembly drawing

\section{Analysis of simulation result}

Simulation step count to 10 / s, the simulation results show that the effect is the best when the angle is zero between blade and paper Bo Pan Angle is zero cutting, and the agency's trajectory can satisfy the requirements of cutting. To make sure the cutting knife and conveyor chain cooperate well, conveyor chain around $130^{\circ}$ every 0.5 seconds. The result of simulation shows that the seedling mechanism satisfies the requirement of cooperation. The motor speed is $100 \mathrm{r} / \mathrm{min}$ and the cutting speed up to 120 / min.

\section{Conclusions}

Taking seedling mechanism as the research object, based on the current development situation, and seedling mechanism is designed, which combined with guide tube. This mechanism can cut paper pot seedling accurately and send single pot into the guide tube. Based on UG, the modeling and simulation analysis are down, and the results show that the design is reasonable; the expected 
requirement can be achieved, so it can provide the theoretical basis for the development of the automatic maize transplanting machine.

Item number: innovation team of Plant pot seedling, 2014TD010

\section{Reference}

[1] Wang Junling, Gao Yuzhi, Li chenghua. Vegetable transplanting mechanization production present situation and the development direction of [J]. Journal of agricultural mechanization research, 44-45 (2004).

[2] $\mathrm{Wu} \mathrm{Ke}$, Chen Yongcheng, finish the new victory. Several typical transplanting machine [J]. Journal of xinjiang agricultural mechanization, 3 (2009), p. 24-26.

[3] Cui Wei, Yan Hua, Gao Xiwen, etc. The development of dry land transplanting machinery [J]. The present situation and development trend of agricultural engineering, 2 (2015), p.27-30.

[4] Zhu Yuncai. 2 ZDF tubular type semi-automatic guide seedlings transplanting machine [J]. Journal of Jiangsu agricultural machinery and agronomy, 1 (2000), p 28.

[5] Sun Yujing, Wu Hua. 2 zt transplanting machine study design [J]. Journal of agricultural mechanization research, 1 (1999), p. 53-54.

[6] Wu Fuhua, han-ping MAO, jian-ping hu, etc. Automatic hole tray seedlings transplanting machine design and test [J]. Journal of agricultural mechanization research, 4 (2013), p. 162-165, 173.

[7] Gu Wenjun, Cao Weibin, li Weimin, etc. The hole tray seedling plunger type taking seedling mechanism of automation control system design [J]. Journal of agricultural mechanization research, 12 (2013), p. 114-117.

[8] Xu Liming, Zhang Tiezhong. Corn seedling transplanting machine structure design [J]. Journal of China agricultural university, 4 (2000), p. 62-64.

[9] Ye Bingliang, Liu An, Yu Gaohong, etc. Vegetables pot seedling transplanting machine taking seedling mechanism human-computer interaction parameters optimization and test [J]. Journal of agricultural machinery, 2 (2013), p. 63-68. 